\title{
Evolución de un evento de surgencia frente a punta Curaumilla, Valparaíso
}

\author{
Nelson Silva \& Alexander Valdenegro \\ Escuela de Ciencias del Mar \\ Pontificia Universidad Católica de Valparaíso \\ Casilla 1020. Valparaíso, Chile \\ E-mail: nsilva@ucv.cl; avaldenegrom@ hotmail.cl
}

\begin{abstract}
RESUMEN. Se analiza la evolución de un evento de surgencia costera (16 al 20 de enero de 1986), frente a punta Curaumilla $\left(33^{\circ} 06^{\prime} \mathrm{S}\right)$, sobre la base de la distribución espacial y temporal de temperatura, salinidad, oxígeno disuelto, nutrientes (nitrato, fosfato y silicato), viento y transporte de Ekman. Como información complementaria se utilizó imágenes satelitales de temperatura superficial del mar. Los resultados mostraron que los vientos fueron fluctuantes y predominantemente del S y SW, permitiendo observar las fases de inicio y madurez de un evento de surgencia costera debido a la coacción del viento y el comienzo de la fase de relajación. La fase de inicio se caracterizó por un aumento del viento S y SW del transporte Ekman, un ascenso en la costa de la termoclina estacional y una pluma de aguas frías superficiales $\left(<14^{\circ} \mathrm{C}\right)$ en dirección $45-55^{\circ}$ a la izquierda de la línea de costa. La fase de madurez se caracterizó por la presencia de vientos fuertes $\left(>10 \mathrm{~m} \cdot \mathrm{s}^{-1}\right)$, altos valores promedio del transporte de Ekman $\left(>1.000 \mathrm{~m}^{3} \cdot \mathrm{s}^{-1}\right.$ por $1.000 \mathrm{~m}$ de costa), disminución de la temperatura $\left(<14^{\circ} \mathrm{C}\right)$ y oxígeno disuelto $\left(<4 \mathrm{ml} \cdot \mathrm{L}^{-1}\right)$ y aumento de los valores de salinidad ( $>34,4$ psu) y nutrientes (fosfato $>2,0 \mu \mathrm{M}$; nitrato $>15 \mu \mathrm{M}$; silicato $>10 \mu \mathrm{M}$ ) en la zona costera. La fase de declinación se observó parcialmente, debido a que el viento no se relajó lo suficiente hacia el final del período de muestreo. Sin embargo, las imágenes satelitales de temperatura superficial del mar de los días siguientes ( 23 y 24 de enero), mostraron claramente la diminución del área cubierta por la aguas frías de surgencia. La masa de agua desplazada hacia el océano fue de características subantárticas y la masa de agua que ascendió hacia la costa fue de características ecuatoriales subsuperficiales.
\end{abstract}

Palabras claves: surgencia, Curaumilla, Chile.

\section{Evolution of an upwelling event off Punta Curaumilla, Valparaíso}

\begin{abstract}
The beginning, maturity and relaxation phases of a coastal upwelling event (16 to 20 January 1986), off punta Curaumilla $\left(33^{\circ} 06^{\prime} \mathrm{S}\right)$, were characterized. This characterization was based on the spatial and time distribution of temperature, salinity, dissolved oxygen, nutrients (nitrate, phosphate and silicate), wind and Ekman transport. Satellite images of sea surface temperature were used as complementary information. The results showed that the winds were fluctuating and mainly blowing from the south and southwest, so it was possible to observe the initial and mature phases and the beginning of the relaxation phase. The initial phase was characterized by an increase of the south and southwest wind and the Ekman transport, a rise of the seasonal thermocline at the coast and the presence of a cold surface water plume $45-55^{\circ}$ towards the left of the coastline. The mature phase was characterized by the presence of strong winds $\left(>10 \mathrm{~m} \cdot \mathrm{s}^{-1}\right)$, high mean Ekman transport $\left(>1,000 \mathrm{~m}^{3} \cdot \mathrm{s}^{-1}\right.$ per 1,000 $\mathrm{m}$ of coast), a lowering of the temperature $\left(<14^{\circ} \mathrm{C}\right)$ and dissolved oxygen and an increase of the salinity $(>34.4 \mathrm{psu})$ and nutrients (phosphate $>2.0 \mu \mathrm{M}$; nitrate $>15 \mu \mathrm{M}$; silicate $>10 \mu \mathrm{M}$ ) at the coastal margin. The declination phase was partially observed, because the wind did not relax enough during the sampling period. However, the surface temperature satellite images on 23 and 24 January, clearly showed a decrease of the area covered with cold upwelled water. The water mass displaced towards the ocean had Subantarctic characteristics and the water mass upwelled to the surface, had Equatorial Subsurface characteristics.
\end{abstract}

Key words: upwelling, Curaumilla, Chile. 


\section{INTRODUCCIÓN}

Una de las primeras descripciones de eventos de surgencia en aguas de la costa de Chile fue realizada por Brandhorst (1963), en su análisis de las condiciones oceanográficas entre punta Curaumilla $\left(33^{\circ} 05^{\prime} \mathrm{S}\right)$ y el golfo de Arauco $\left(37^{\circ} 15^{\prime} \mathrm{S}\right)$. Este autor, señaló en forma conceptual el efecto de los vientos del S y SW sobre las aguas superficiales, indicando que el resultado final era un ascenso hacia superficie de aguas subsuperficiales frías, salinas y pobres en oxígeno disuelto. Según en esta técnica, Brandhorst (1963), describió a punta Curaumilla, punta Talca $\left(33^{\circ} 25^{\prime} \mathrm{S}\right)$, punta Toro $\left(33^{\circ} 47^{\prime} \mathrm{S}\right)$, punta

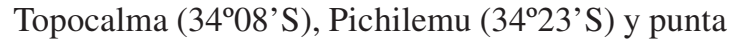
Nugurne (3559'S), como zonas afectadas por eventos de surgencia debido al efecto del viento.

Trabajos posteriores ampliaron el conocimiento sobre el fenómeno de surgencia en aguas chilenas, ya sea describiendo sus características oceanográficas y frecuencia (Silva, 1973; Sievers \& Silva, 1979; Fonseca \& Farías, 1987; Cáceres, 1992; Sievers \& Vega, 2000; Blanco et al., 2001), su efecto sobre las comunidades marinas (Arcos \& Salamanca, 1984; Rodríguez et al., 1991; Marín et al., 1993; Montecinos \& Balbontín, 1993; Cubillos \& Fuenzalida,1994; Montecino et al., 1996; Tam \& Carrasco, 1999; Escribano \& Hidalgo, 2000;
Montecino \& Quiroz, 2000; Ulloa et al., 2001; Escribano et al., 2001), o proponiendo modelos matemáticos que explican su dinámica (Vergara, 1991, 1992; Figueroa \& Mofat, 2000).

En el caso de punta Curaumilla, Silva (1973) indica que ésta se caracteriza por presentar eventos de surgencia no permanentes y aperiódicos, los cuales están íntimamente relacionados con la presencia de vientos del S y SW. La evolución de estos eventos en esta zona sólo ha sido estudiada al nivel de semanas, en una estación fija (Sievers \& Vega, 2000), por lo que el seguimiento de un evento a una frecuencia mayor aún no ha sido realizado. El presente trabajo tiene como objetivo efectuar un análisis de la evolución, al nivel de días, de un evento de surgencia, frente a punta Curaumilla.

\section{MATERIALES Y MÉTODOS}

La zona de estudio se ubicó al sur de Valparaíso, frente a punta Curaumilla entre $33^{\circ} 00^{\prime} \mathrm{S}$ y $33^{\circ} 10^{\prime} \mathrm{S}$ y hasta alrededor de $27 \mathrm{~km}$ (15 millas náuticas), mar afuera (Fig. 1). Como el desarrollo del experimento estuvo asociado a la presencia de un evento de surgencia debido al viento, se utilizó la información de la carta de predicción meteorológica e imágenes satelitales de temperatura superficial del mar (TSM),

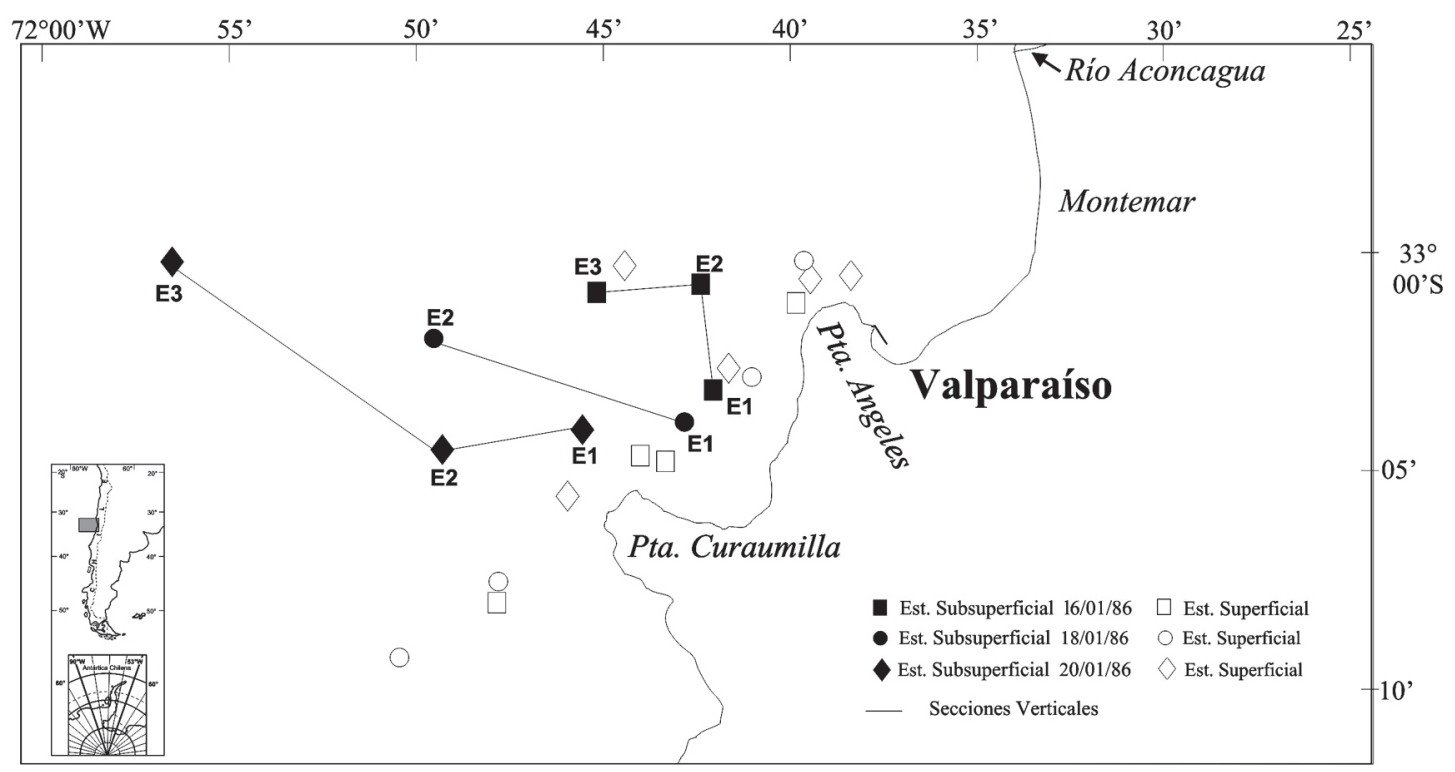

Figura 1. Ubicación geográfica de las estaciones oceanográficas superficiales y subsuperficiales.

Figure 1. Geographical distribution of surface and subsurface oceanographic stations. 
como alerta temprana para decidir cuando iniciar (presencia de vientos sobre 20 nudos del S a SW) y donde efectuar el muestreo (zona costera con temperaturas 1 a $2^{\circ} \mathrm{C}$ menores que las de la zona oceánica). Una vez iniciado el muestreo, éste se prolongaría por cinco días, tiempo que se estimó suficiente para alcanzar la fase de relajación de la surgencia.

Este sistema de alerta anterior mostró la conveniencia de iniciar el muestreo, con el B/E "Tiberíades", el 16 de enero de 1986 y se extendió a los días 18 y 20, haciéndose un muestreo en una sección con 2 ó 3 estaciones oceanográficas subsuperficiales (0-120 m) orientadas en dirección NW. Junto a lo anterior, se realizó un muestreo superficial ( $0 \mathrm{~m}$ ), en varias estaciones adicionales (Fig. 1). En cada estación oceanográfica se registró la temperatura con termómetros de inversión y se tomaron muestras de agua con botellas Nansen para los análisis de salinidad, oxígeno disuelto, nitrato, fosfato y silicato.

Las muestras de salinidad se analizaron con un salinómetro AutoLab y las de oxígeno disuelto, se fijaron a bordo y se analizaron de acuerdo al método de Winkler modificado por Carpenter (1965). Los valores de saturación de oxígeno se calcularon según el algoritmo de Weiss (1970). Los nutrientes (fosfato, nitrato y silicato), se fijaron con dos gotas de cloroformo y se refrigeraron hasta su análisis mediante un autoanalizador, según las técnicas de Atlas et al. (1971).

Las masas de agua presentes en la zona de estudio, se identificaron mediante diagramas T-S y su participación porcentual en la mezcla se calculó mediante el método del triángulo de mezcla y los valores tipos indicados por Silva \& Konow (1975).

Paralelamente, se obtuvieron los registros de viento (dirección y magnitud) cada 3 h en el faro Punta de Angeles, Valparaíso. Con estos registros se calculó el transporte de Ekman o índice de surgencia instantáneo (Bakun, 1978). Además se estimó el transporte de Ekman promedio, para lo cual se filtró la serie de valores instantáneos con un promedio móvil de ocho pesos, a fin de eliminar el efecto de frecuencias menores a $24 \mathrm{~h}$. Los valores del transporte de Ekman se expresaron en $\mathrm{m}^{3} \cdot \mathrm{s}^{-1}$ por 1.000 metros de costa, que en el texto sólo se indicarán como $\mathrm{m}^{3} \cdot \mathrm{s}^{-1}$.

Además, se estimó la velocidad vertical de ascenso de la columna de agua (w), en función del estrés del viento $(\tau)$, de acuerdo a las siguientes ecuaciones:

$$
\begin{gathered}
w=\frac{\tau}{\rho_{w} \cdot f \cdot h} \\
\tau=\rho_{a} \cdot C d_{10} \cdot|v| \cdot v
\end{gathered}
$$

donde f es el parámetro de Coriolis, h la profundidad de la columna de agua afectada por el viento (en este caso se consideró la columna sobre la isoterma de $12^{\circ} \mathrm{C}$ ), v es la componente latitudinal de la intensidad del viento, $\rho_{w}$ la densidad del agua de mar, $\rho_{\mathrm{a}}$ es la densidad del aire $\left(1,24 \mathrm{~kg} \cdot \mathrm{m}^{-3}\right), \mathrm{Cd}_{10}$ coeficiente de arrastre del viento estimado como: $\mathrm{Cd}_{10}=(0,8+0,065 \cdot \mathrm{V}) \cdot 10^{-3}$, donde $\mathrm{V}$ es la velocidad del viento $\left(\mathrm{m} \cdot \mathrm{s}^{-1}\right)$ a $10 \mathrm{~m}$ del nivel del mar $(\mathrm{Wu}$, 1982).

El espesor de la capa de Ekman (DE), se calculó de acuerdo a:

$$
D E=0,1 \frac{\sqrt{\frac{\tau}{\rho_{w}}}}{f}
$$

Para seguir la evolución del evento de surgencia con una mayor sinopticidad y cobertura espacial, se utilizó como complemento a la información de la estructura térmica superficial registrada durante el crucero, imágenes TSM obtenidas por el satélite NOAA-F, correspondientes a los días previos, durante y posteriores al muestreo. Estas imágenes fueron procesadas por el Laboratorio SATAL de la Pontificia Universidad Católica de Valparaíso.

\section{RESULTADOS}

Después del período de viento suave del $\mathrm{S}$ y $\mathrm{SW}$ $\left(<5 \mathrm{~m} \cdot \mathrm{s}^{-1}\right)$ del 10 y 11 de enero 1986, éstos repuntaron el día $12\left(>10 \mathrm{~m} \cdot \mathrm{s}^{-1}\right)$, para relajarse nuevamente durante el 14 (Figs. 2a y 2b). De acuerdo a las TSM, la temperatura en la zona costera frente a punta Curaumilla fue entre 17 a $19^{\circ} \mathrm{C}$, con escasa presencia de valores menores a $17^{\circ} \mathrm{C}$ entre punta Curaumilla y Quintero (Fig. 3a).

Desde la tarde del 15 de enero, el viento comenzó a aumentar rápidamente en intensidad y por lo tanto el transporte Ekman. Esto provocó un aumento del transporte de una media de $250 \mathrm{~m}^{3} \cdot \mathrm{s}^{-1}$ el $14 \mathrm{de}$ enero, a valores medios de $800 \mathrm{~m}^{3} \cdot \mathrm{s}^{-1}$ el día 15 , alcanzando valores instantáneos máximos de 2.000 $\mathrm{m}^{3} \cdot \mathrm{s}^{-1}$ en la tarde de ese día (Fig. 2c). 
El 16, que correspondió al primer día de muestreo, el viento y el transporte Ekman se mantuvieron en intensidad respecto al día anterior (Fig. 2c). El valor de velocidad vertical estimado el 16, fue de $0,02 \mathrm{~cm} \cdot \mathrm{s}^{-1}$ y la profundidad de la capa de Ekman de 9,2 m.

La distribución superficial de la temperatura in situ presentó un gradiente horizontal paralelo a la costa de aproximadamente $0,8^{\circ} \mathrm{C} \cdot \mathrm{km}^{-1}\left(1,4^{\circ} \mathrm{C} / \mathrm{milla}\right.$ naútica), con las temperaturas más altas $\left(>17^{\circ} \mathrm{C}\right)$ hacia la zona oceánica y las más bajas $\left(<15^{\circ} \mathrm{C}\right)$ en el borde costero (Fig. 4a). La TSM, mostró un filamento de agua de menor temperatura $\left(14 \mathrm{a} 16^{\circ} \mathrm{C}\right)$ (Fig. 3b).
La distribución de salinidad, oxígeno disuelto y nutrientes en superficie fue más homogénea, no observándose un gradiente costa-océano marcado como en la temperatura. Las concentraciones de nutrientes fueron bajas, con algunos valores superiores a 1 y $5 \mu \mathrm{M}$ de fosfato y nitrato respectivamente (Figs. 4b a 4e), situación que no ocurrió con el silicato donde fue menor de $1 \mu \mathrm{M}$ (Fig. 4f).

La distribución en profundidad de temperatura presentó una termoclina estacional bien definida en la zona oceánica de la sección, con un gradiente máximo de $0,4^{\circ} \mathrm{C} \cdot \mathrm{m}^{-1}$, que declinó a $0,1^{\circ} \mathrm{C} \cdot \mathrm{m}^{-1}$ hacia la zona costera (Fig. 5a). La distribución vertical de salinidad, oxígeno disuelto y nutrientes, se mostró

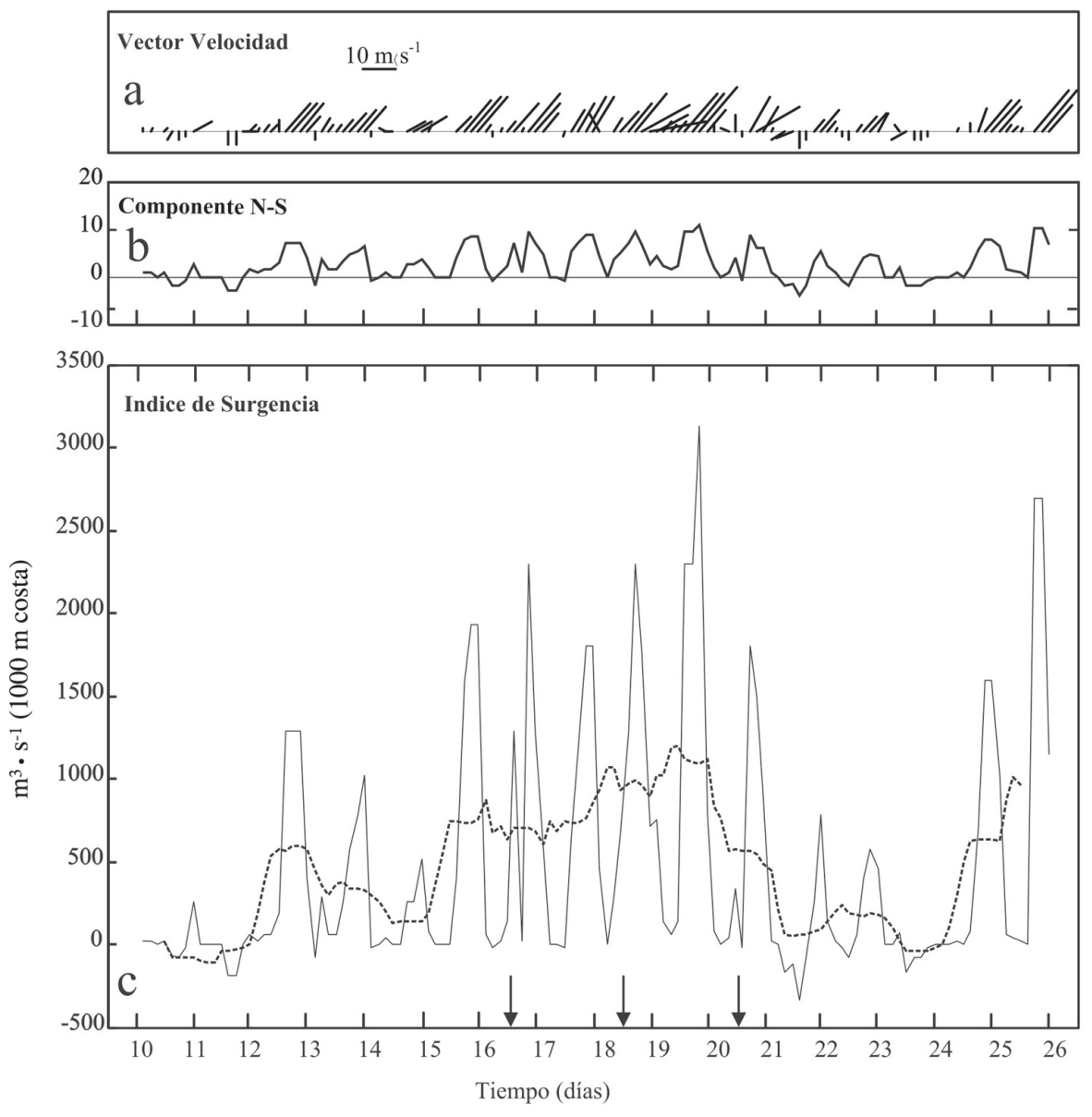

Figura 2. Serie de tiempo para a) viento observado, b) componente norte-sur y c) transporte Ekman, durante los días 10 al 25 de enero de 1986, en punta Angeles. La línea segmentada indica el transporte Ekman filtrado con un promedio móvil de 8 pesos y las flechas indican los cruceros oceanográficos.

Figure 2. Time series of observed a) wind, b) north-south wind component and c) Ekman transport, from 10 to 25 January 1986, at punta Angeles. The dashed line indicates the Ekman transport filtered with an 8 weight box car average. The arrows indicates the oceanographic cruises. 


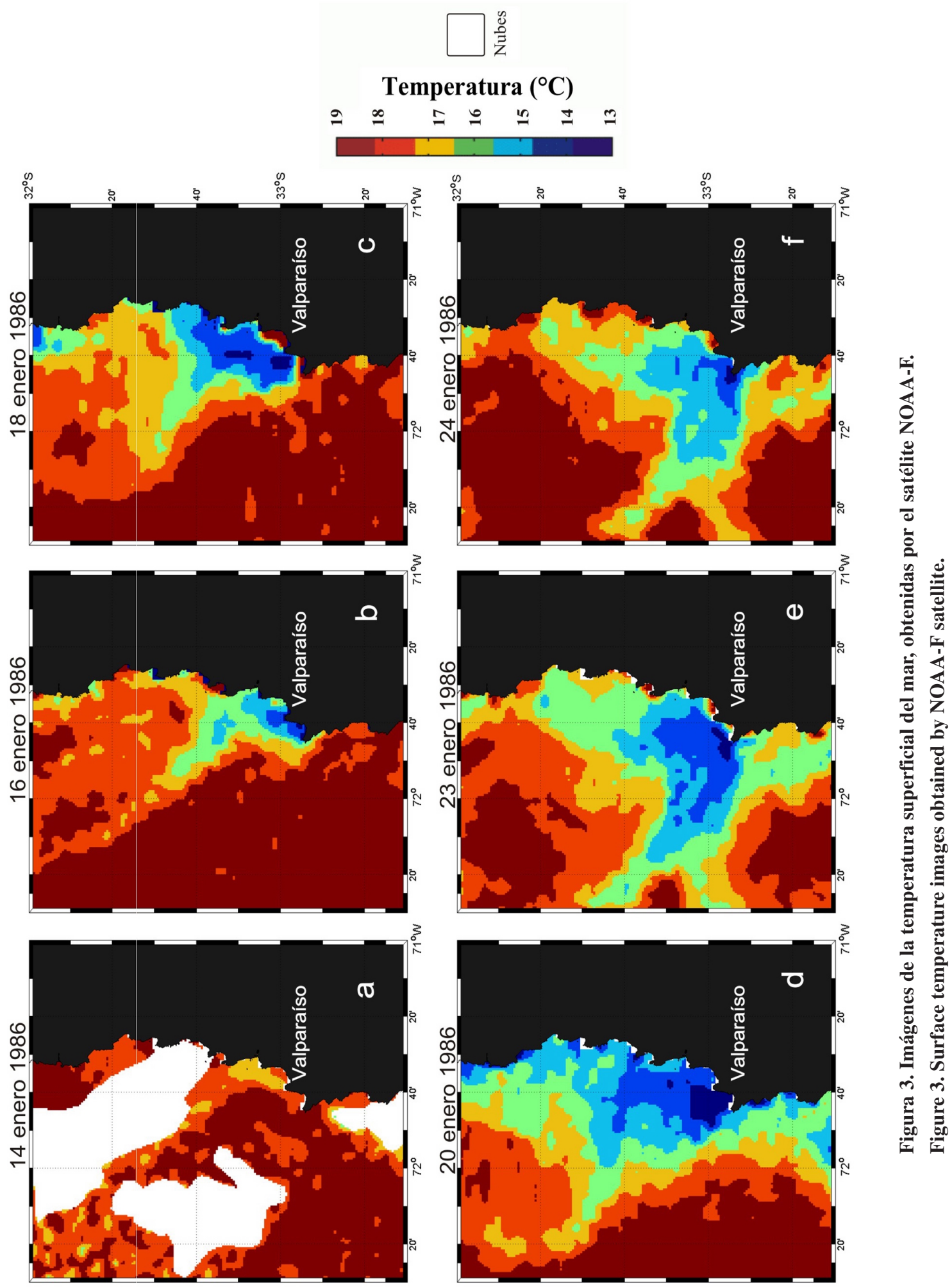



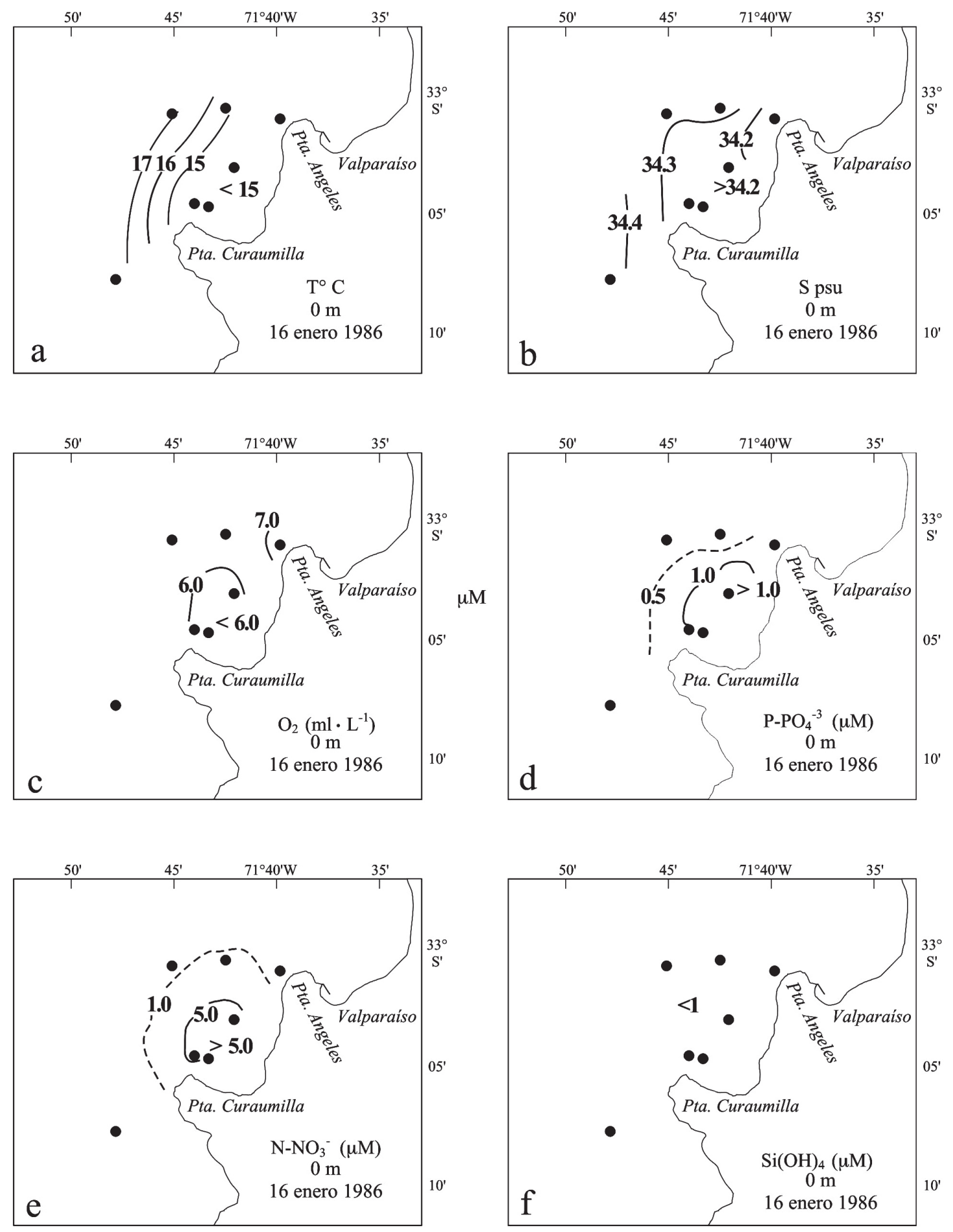

Figura 4. Distribución horizontal de a) temperatura, b) salinidad, c) oxígeno disuelto, d) fosfato, e) nitrato y f) silicato, el 16 de enero de 1986.

Figure 4. Horizontal distribution of a) temperature, b) salinity, c) dissolved oxygen, d) phosphate, e) nitrate and f) silicate on 16 January 1986. 

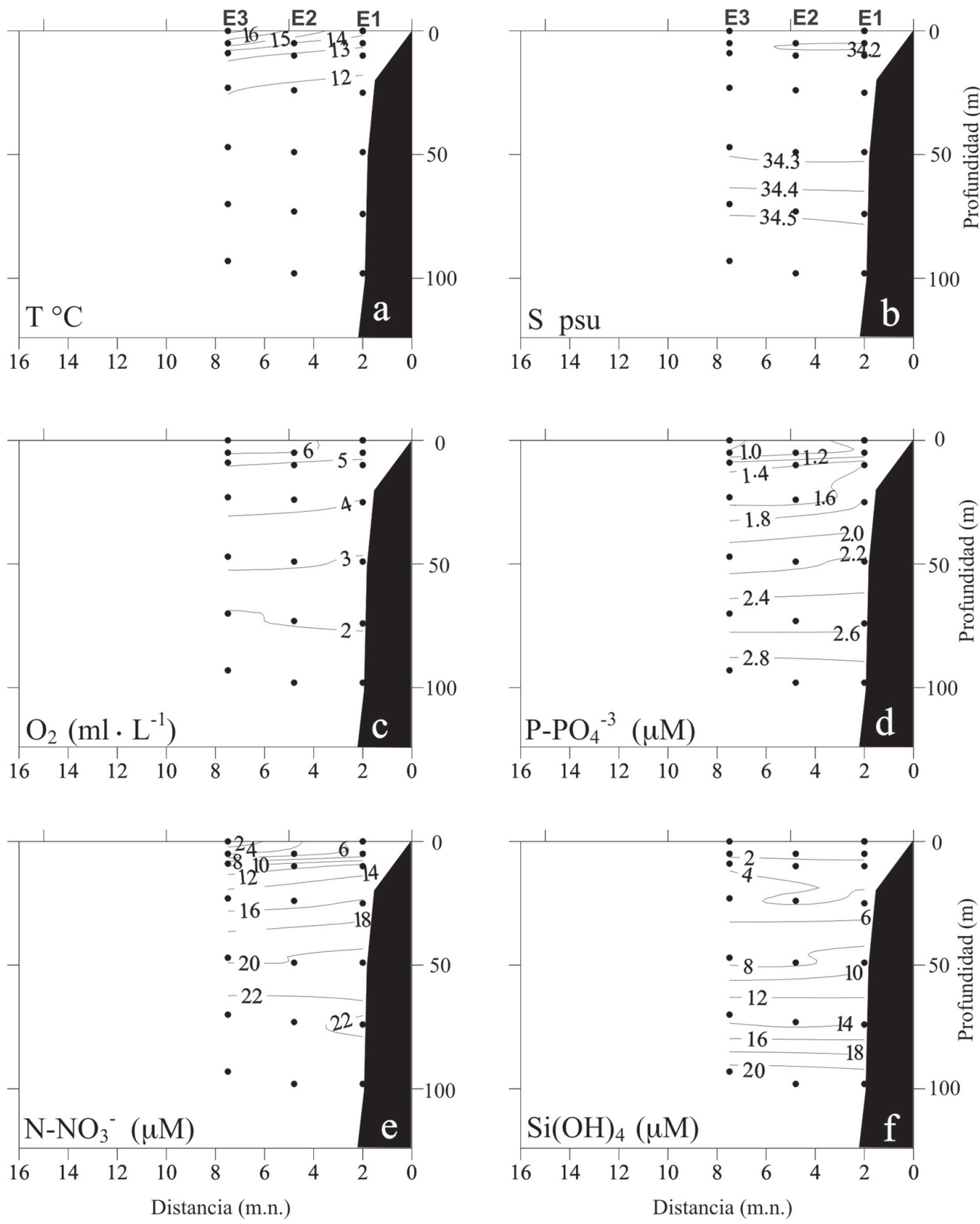

Figura 5. Distribución vertical de a) temperatura, b) salinidad, c) oxígeno disuelto, d) fosfato, e) nitrato y f) silicato, el 16 de enero de 1986.

Figure 5. Vertical distribution of a) temperature, b) salinity, c) dissolved oxygen, d) phosphate, e) nitrate and f) silicate on 16 January 1986. 
estratificada, con una distribución de las isolíneas más bien horizontal y un leve ascenso en los primeros $10 \mathrm{~m}$ de la parte costera de la sección (Figs. 5b a 5f).

El porcentaje de masas de agua, presentó una distribución horizontal estratificada, con núcleos de máximos valores de 30\% de Agua Subtropical (AST) en superficie, $70 \%$ de Agua Subantártica (ASAA) a unos $25 \mathrm{~m}$ y $70 \%$ de Agua Ecuatorial Subsuperficial (AESS) alrededor de $100 \mathrm{~m}$ de profundidad (Figs. 6a a 6c).

Los días 17 y 18, el viento local, que continuó presentándose en forma de pulsos con mayor intensidad en las tardes, aumentó levemente respecto a los días previos y también aumentó el transporte Ekman, que en promedio sobrepasó los $1.000 \mathrm{~m}^{3} \cdot \mathrm{s}^{-1}$
(Figs. 2a a 2c). La velocidad vertical (w) correspondiente al día 18 fue de $0,07 \mathrm{~cm} \cdot \mathrm{s}^{-1} \mathrm{y}$ la profundidad de la capa de Ekman de $21 \mathrm{~m}$. La TSM mostró un aumento en la cobertura espacial de bajas temperaturas superficiales $\left(<13^{\circ} \mathrm{C}\right)$, en la franja costera (Fig. 3c).

La distribución superficial de temperatura in situ y oxígeno disuelto del 18 de enero, presentó los menores valores en el borde costero y los mayores en la zona oceánica (Figs. 7a y 7c). La salinidad y nutrientes presentaron los mayores valores en la franja costera y los menores en la zona oceánica (Figs. 7b a 7f), lo cual generó un gradiente horizontal costa-océano.

En la distribución vertical se observó un cambio respecto a la distribución del 16 de enero, obser-
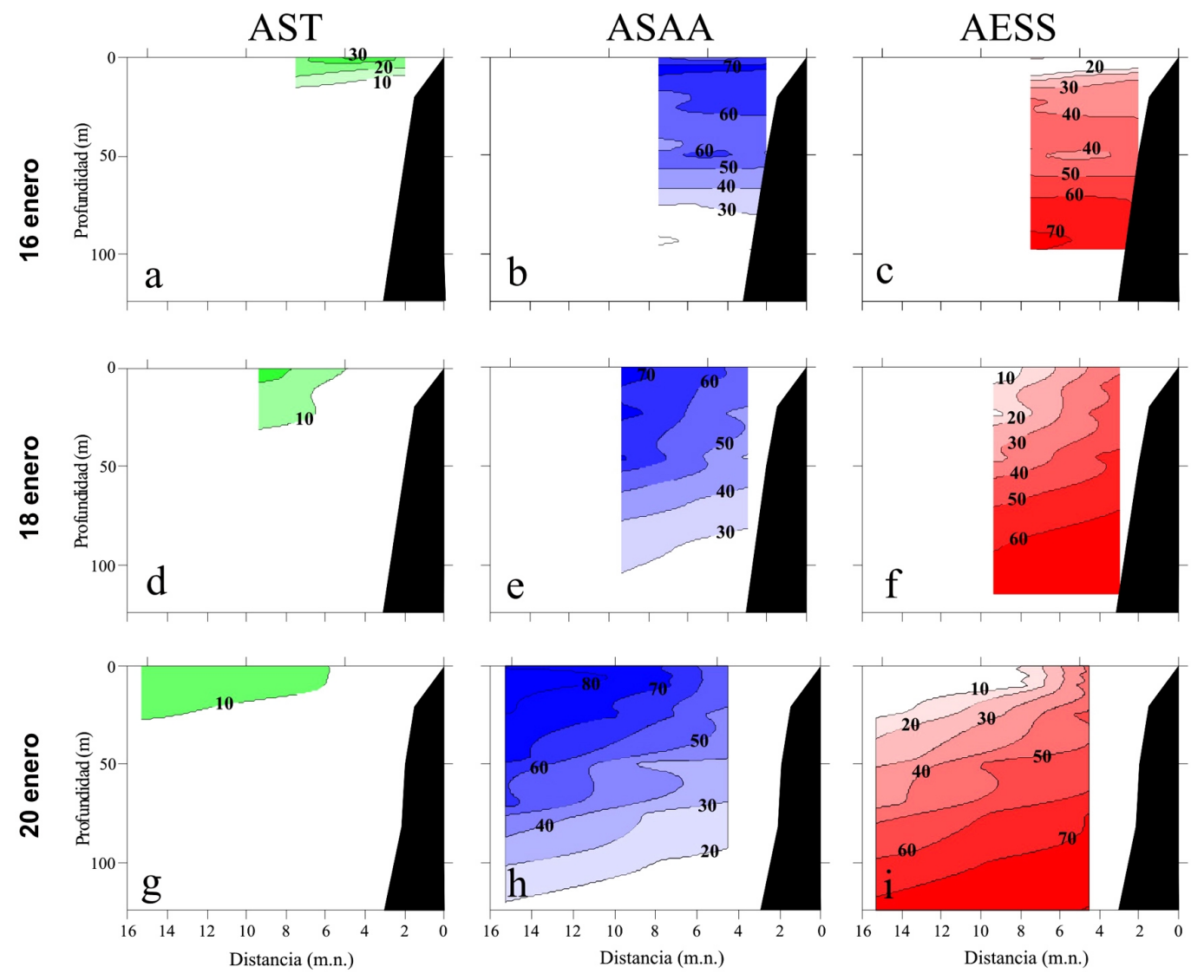

Figura 6. Diagramas T-S y participación porcentual en la mezcla de las masas de agua Subtropical (AST), Subantártica (ASAA) y Ecuatorial Subsuperficial (AESS), frente a punta Curaumilla durante los días 16 (a, b, c), 18 (d, e, f) y 20 (g, h, i), de enero de 1986.

Figure 6. T-S diagrams and percentage participation in the mixture of Subtropical (AST), Subantarctic (ASAA) and Equatorial Subsurface (AESS) water masses off punta Curaumilla, during 16, (a, b, c ), 18 (d, e, f) and 20 January (g, h, i), 1986. 

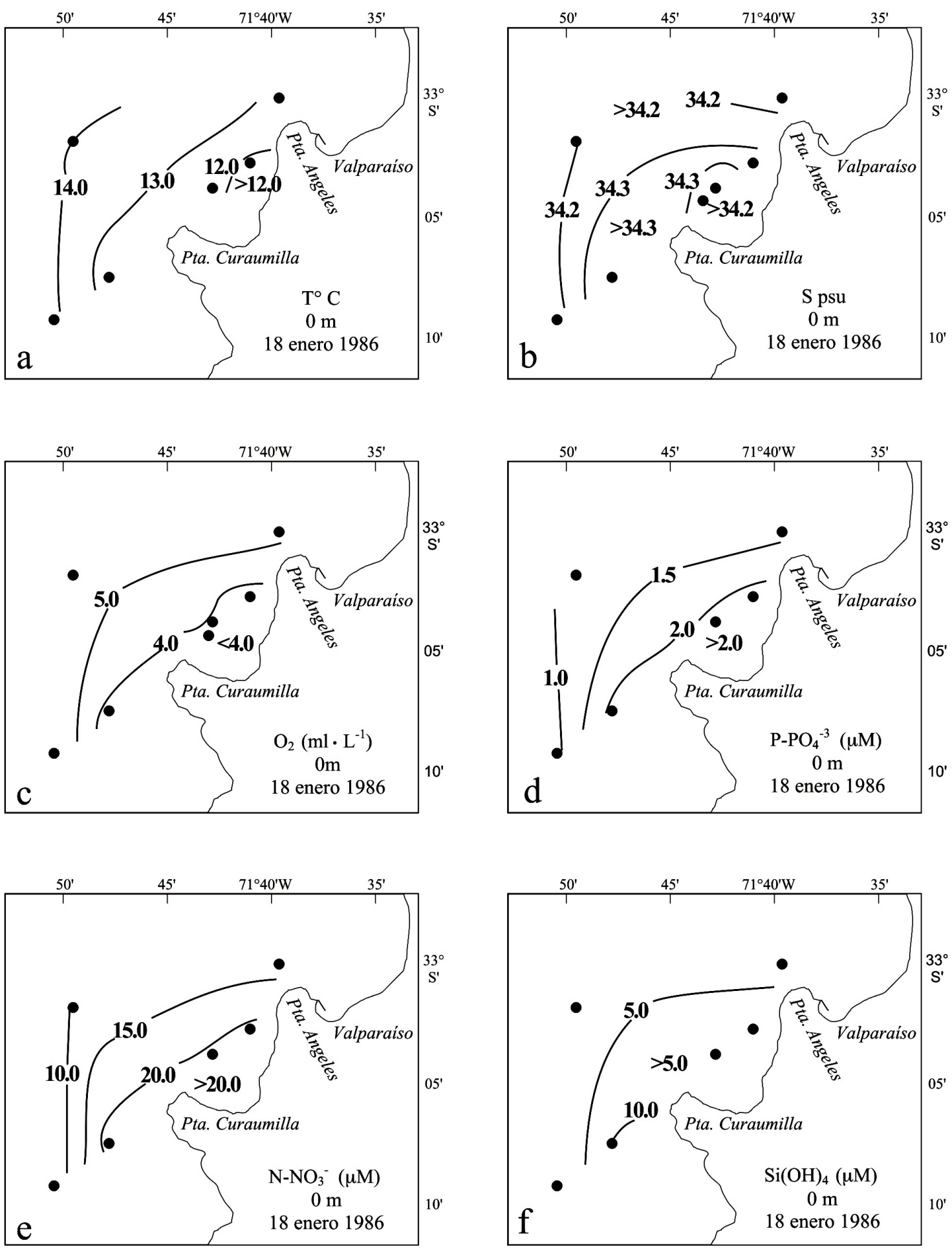

Figura 7. Distribución horizontal de a) temperatura, b) salinidad, c) oxígeno disuelto, d) fosfato, e) nitrato y f) silicato, el 18 de enero de 1986.

Figure 7. Horizontal distribution of a) temperature, b) salinity, c) dissolved oxygen, d) phosphate, e) nitrate and f) silicate on 18 January 1986. 
vándose una distribución ascendente de las isolíneas de temperatura, salinidad, oxígeno disuelto y nutrientes hacia la costa, algunas de las cuales llegaron a intersectar la superficie (Fig. 8a a 8f). Esto provocó, en general, un aumento de salinidad de 34,2 a 34,3 psu, disminución del oxígeno disuelto, de 6 a
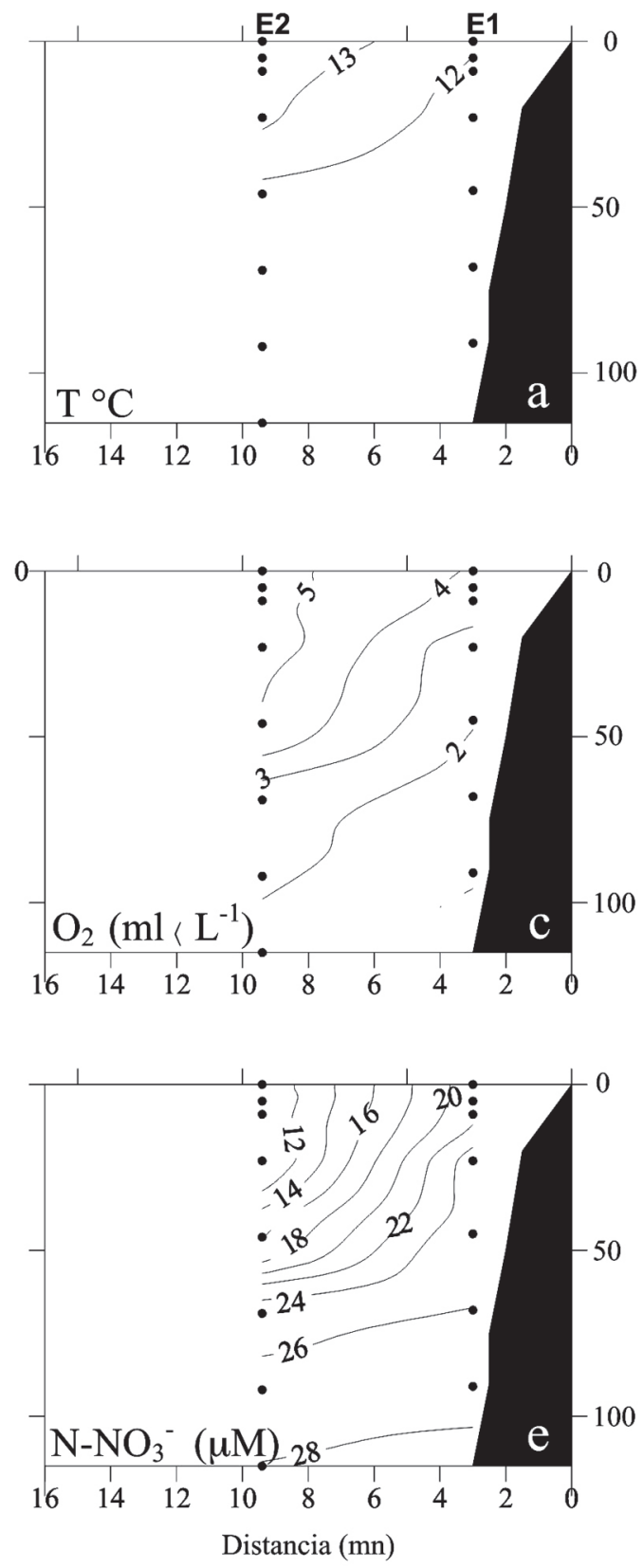

$<4 \mathrm{ml} \cdot \mathrm{L}^{-1}$ (100 a $60 \%$ de saturación) y aumento de las concentraciones de los nutrientes en un orden de magnitud (fosfato de $0,5 \mathrm{a}>2,0 \mu \mathrm{M}$; nitrato de 2 a $>15 \mu \mathrm{M}$; silicato de 2 a $>10 \mu \mathrm{M})$, en la franja costera de Curaumilla (Figs. 8 b a $8 f$ ).

La distribución vertical de las isolíneas del por-
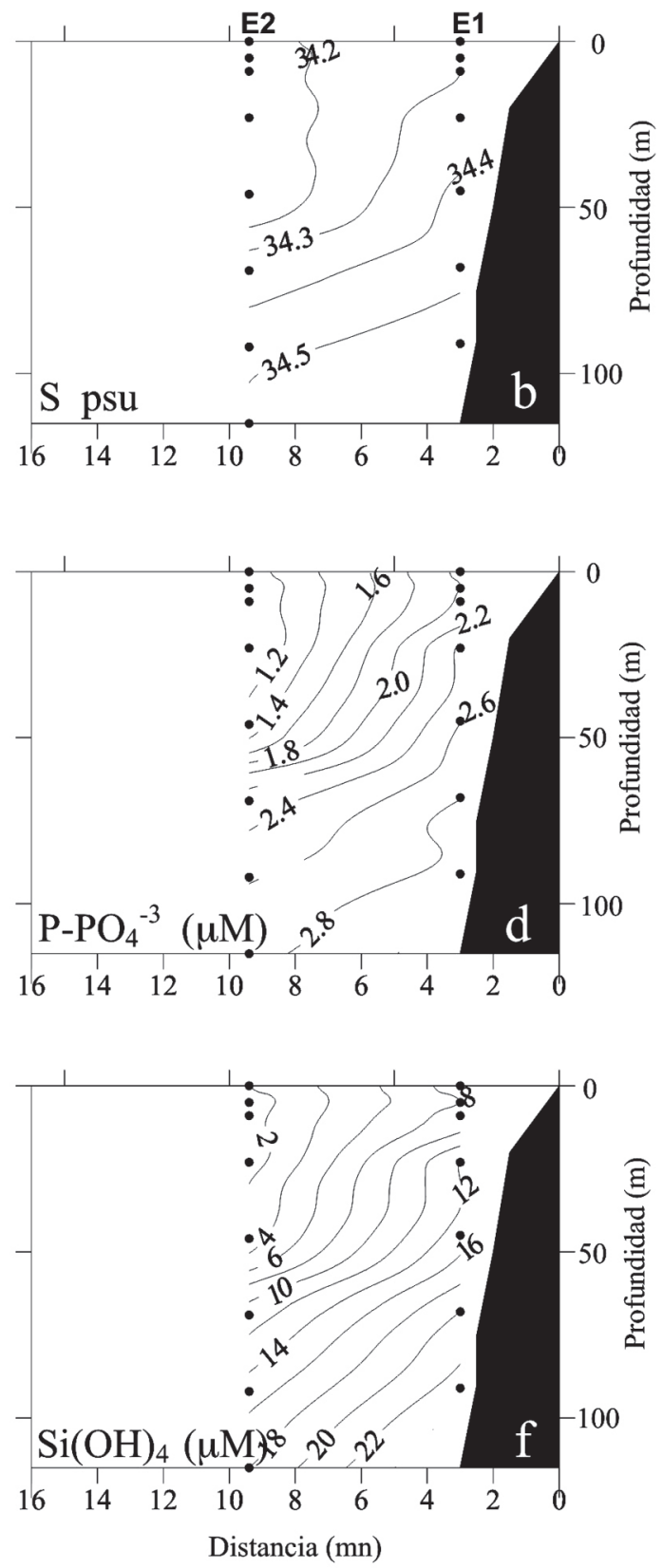

Figura 8. Distribución vertical de a) temperatura, b) salinidad, c) oxígeno disuelto, d) fosfato, e) nitrato y f) silicato, el 18 de enero de 1986.

Figure 8. Vertical distribution of a) temperature, b) salinity, c) dissolved oxygen, d) phosphate, e) nitrate and f) silicate on 18 January 1986. 
centaje de participación de las masas de agua en la mezcla, también mostró una distribución vertical ascendente donde las isolíneas de $60 \%$ de ASAA y $30 \%$ de AESS interceptaron la superficie (Figs. 6d у 6 e).

El 20 de enero, el viento SW disminuyó notablemente, presentando incluso algunas inversiones ocasionales en su dirección y el transporte Ekman promedio disminuyó a $600 \mathrm{~m}^{3} \cdot \mathrm{s}^{-1}$ (Figs. 2a a 2c). El valor de velocidad vertical del día 20 fue de 0,001 $\mathrm{cm} \cdot \mathrm{s}^{-1} \mathrm{y}$ la profundidad de la capa de Ekman de $3 \mathrm{~m}$. La imagen de TSM (Fig. 3d) mostró que las condiciones térmicas superficiales aún se mantenían y el área que abarcó el agua fría fue mayor que la del día 18 (Figs. 3c y 3d).

La distribución de temperatura in situ mostró un desplazamiento hacia la costa de las isotermas mayores de $13^{\circ} \mathrm{C}$ y el restablecimiento de la termoclina estacional (Figs. 9a y 10a). Mientras que las distribuciones superficiales de salinidad, oxígeno disuelto y nutrientes, aún mostraban valores altos (Figs. 9 b a $9 f)$.

La distribución vertical de las isolíneas de salinidad, oxígeno disuelto y nutrientes aún presentaban una inclinación ascendente, aunque menor a la del 18 de enero (Figs. 10b a 10f). Esto provocó que, en general, en la franja costera las concentraciones de oxígeno disuelto aún fueran bajas $(<4,0$ $\left.\mathrm{ml} \cdot \mathrm{L}^{-1}\right)$, y la salinidad y concentración de nutrientes altas (salinidad $>34,3 \mathrm{psu}$; fosfato $>2,0 \mu \mathrm{M}$; nitrato $>15 \mu \mathrm{M}$; silicato $>10 \mu \mathrm{M}$ ) (Figs. $10 \mathrm{~b}$ a $10 \mathrm{f})$.

Los porcentajes de masas de agua, mostraron una distribución vertical ascendente del AESS, manteniendo el desplazamiento del AST y ASAA hacia el océano (Figs. 6g a 6i).

\section{DISCUSIÓN}

Los eventos de surgencia debidos a la coacción del viento pueden ser subdivididos en tres fases: inicio, madurez y relajación. Evidentemente, estas tres fases serán dependientes, tanto en intensidad como en duración, de un sistema equivalente en la ocurrencia e intensidad de los vientos favorables para su generación.

Para el estudio de la evolución de un evento de surgencia es importante poder detectar su inicio y ubicación de éste, a fin de establecer un muestreo adecuado para seguir el desarrollo de sus fases. Para esto, se utilizó conjuntamente la información de: vientos diarios, carta de pronóstico meteorológico para inferir la intensidad de los vientos del día siguiente, e imágenes satelitales de temperatura superficial del mar, para detectar la presencia de zonas de bajas temperaturas en el borde costero. Esta estrategia permitiría tener una alerta temprana del inicio de un evento de surgencia en punta Curaumilla.

El análisis de los registros de vientos del 10 al 14 de enero 1986, mostraba que la componente $S$ de los vientos, era moderada e inferior a $7 \mathrm{~m} \cdot \mathrm{s}^{-1}$ (Fig. 2b), lo que implicaba transporte de Ekman promedio menor de $500 \mathrm{~m}^{3} \cdot \mathrm{s}^{-1}$ (Fig. 2c). La TSM, representada por la imagen del 14 de enero, era, en general, cálida $\left(17-19^{\circ} \mathrm{C}\right)$ (Fig. 3a). Estas características permitían inferir que las condiciones meteorológicas no eran propicias para el desarrollo de un evento de surgencia en punta Curaumilla, ya que las bajas temperaturas en la zona costera que lo caracterizan (Silva, 1973; Sievers \& Silva, 1979; Fonseca \& Farías, 1987), no estaban presentes.

El aumento del viento SW desde la tarde del día 15 (>10 m· $\cdot \mathrm{s}^{-1}$; Figs. 2a y 2b), favoreció el inicio de un evento de surgencia costera. El valor medio del transporte Ekman prácticamente se triplicó del día $14\left(250 \mathrm{~m}^{3} \cdot \mathrm{s}^{-1}\right)$ al día $15\left(800 \mathrm{~m}^{3} \cdot \mathrm{s}^{-1}\right)$ (Fig. 2c). Esta situación se consideró indicadora del inicio de un evento de surgencia, por lo que se dispuso comenzar el muestreo in situ el día 16, que se prolongaría por cinco días, tiempo que se consideró suficiente para alcanzar a observar la fase de relajación.

\section{Fase de inicio del evento de surgencia}

El muestreo in situ del día 16, mostró que una franja de agua de menor temperatura $\left(<15^{\circ} \mathrm{C}\right)$, abarcó la zona entre punta Angeles y punta Curaumilla, generando un gradiente térmico horizontal paralelo a la costa (Fig. 4). Desde el punto de vista térmico, ello implicaba que el evento de surgencia estaba en su fase de inicio. La TSM, de mayor cobertura espacial que el muestreo in situ, mostró un filamento de agua de menor temperatura $\left(<16^{\circ} \mathrm{C}\right)$, de alrededor de $50 \mathrm{~km}$ de largo, alejándose de la costa en un ángulo de $45-55^{\circ}$ entre los 32,6 y 33, $1^{\circ} \mathrm{S}$ (Fig. 3b).

Filamentos de agua fría de similar extensión y dirección a los registrado en punta Curaumilla, también fueron observados por Cáceres (1992), frente a algunas puntas y cabos ubicados entre cabo Carranza (3530'S) y el golfo de Arauco (37º $10^{\prime} \mathrm{S}$ ). De sus figuras, es posible observar que en las zonas aledañas a puntas o cabos, los filamentos suelen te- 

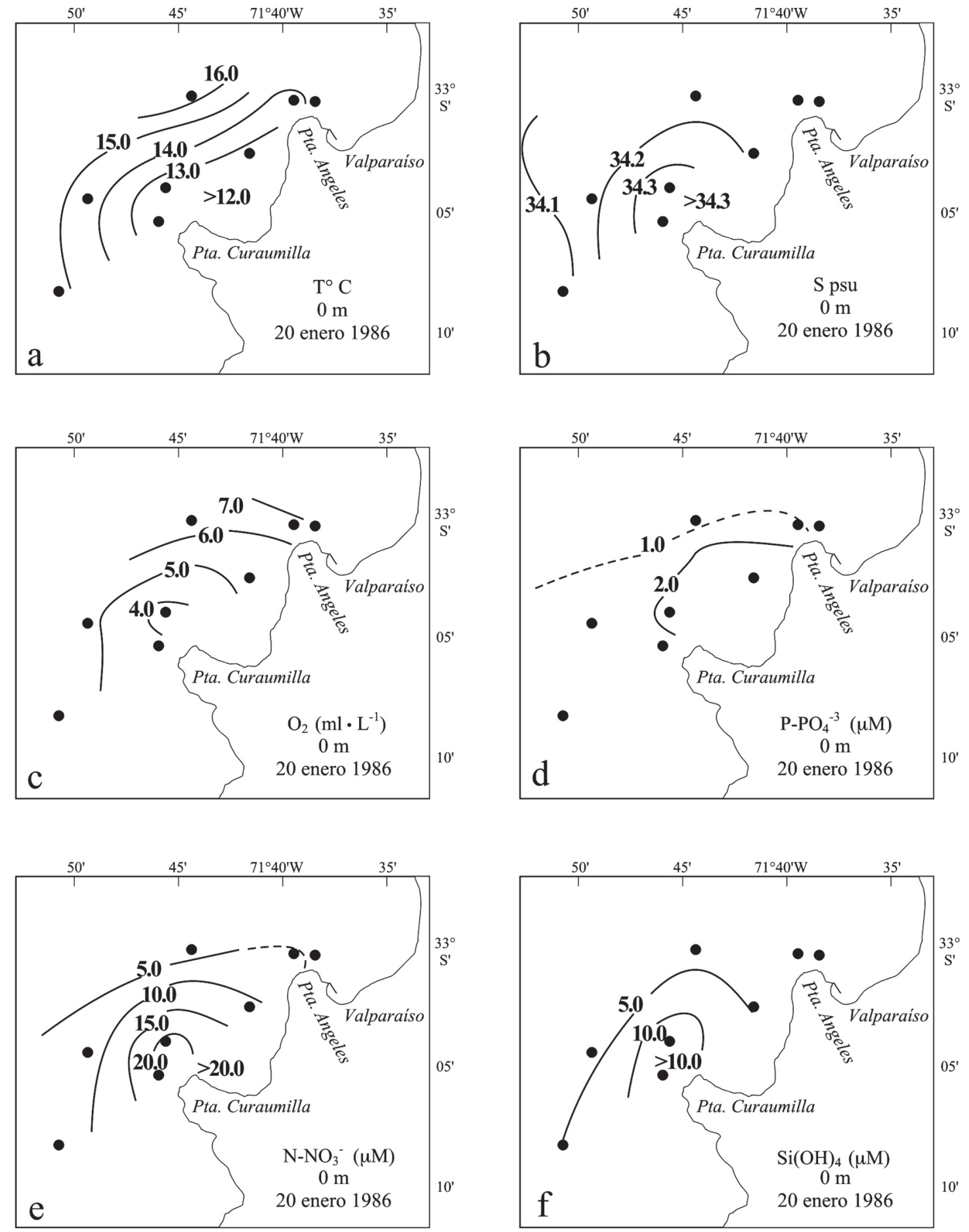

Figura 9. Distribución horizontal de a) temperatura, b) salinidad, c) oxígeno disuelto, d) fosfato, e) nitrato y f) silicato, el 20 de enero de 1986.

Figure 9. Horizontal distribution of a) temperature, b) salinity, c) dissolved oxygen, d) phosphate, e) nitrate and f) silicate on 20 January 201986. 

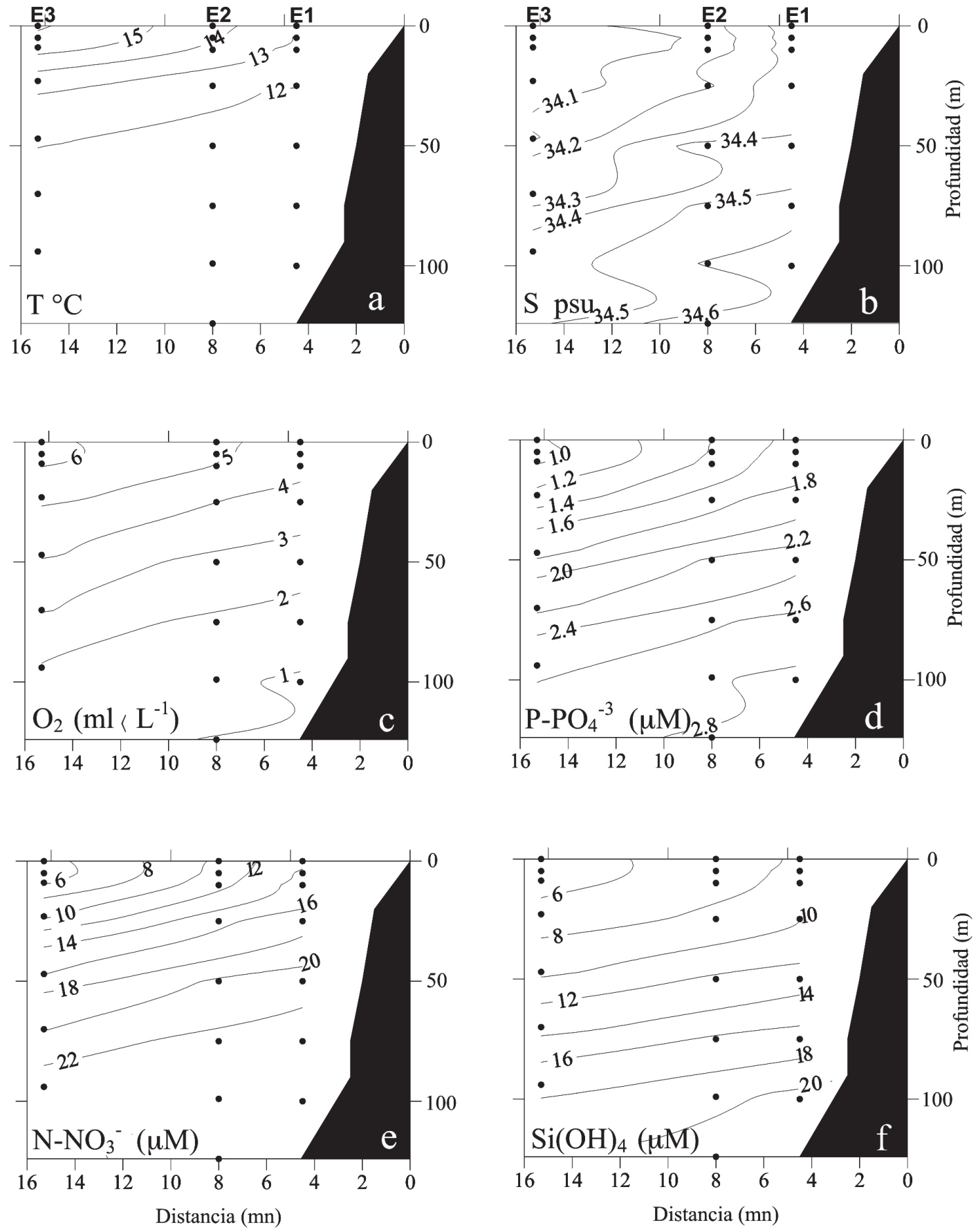

Figura 10. Distribución vertical de a) temperatura, b) salinidad, c) oxígeno disuelto, d) fosfato, e) nitrato y f) silicato, el 20 de enero de 1986.

Figure 10. Vertical distribution of a) temperature, b) salinity, c) dissolved oxygen, d) phosphate, e) nitrate and f) silicate on 20 January 1986. 
ner una dirección de $45-55^{\circ}$ respecto a la línea de costa, mientras que si ellos se presentan frente a cañones batimétricos la dirección es de $90^{\circ}$. Esto implica que además del efecto del viento, las características topográficas de la zona (puntas o cañones) también afectan la dirección de los filamentos de aguas frías propias de eventos de surgencia.

Filamentos de aguas frías producto de la surgencia costera, detectados en imágenes de TSM, también han sido observados frente a la costa de California o de la península Ibérica, donde han alcanzado longitudes de 50 a $300 \mathrm{~km}$ (Hill et al.,1998). Estos filamentos son comunes en zonas de corrientes de borde oriental, como es el caso de punta Curaumilla

Lo anterior, está de acuerdo con lo esperado basado en el modelo de Ekman para un evento de surgencia costera, donde el efecto del viento es un factor importante en su gestación. De hecho, los eventos de surgencia descritos para punta Curaumilla siempre han sido asociados a vientos fuertes del S y SW y al área de la punta (Silva, 1973; Sievers \& Silva 1979; Fonseca \& Farías, 198; Sievers \& Vega, 2000), lo cual evidencia la importancia del efecto del viento y la geometría del área en los eventos de esta zona. De acuerdo a los cálculos teóricos efectuados por Figueroa \& Moffat (2000), frente a punta Curaumilla, la velocidad vertical (surgencia) inducida por el viento es de similar magnitud que la surgencia inducida por efectos topográficos de la zona. Esta punta ha sido descrita como un centro local de surgencia costera (Sievers \& Silva, 1979).

El análisis de la salinidad, oxígeno disuelto y nutrientes, no mostraba la presencia de un gradiente costa-océano (Figs. 4b a 4e), lo que junto con una distribución vertical estratificada horizontal de esas variables, no definían claramente la presencia de un proceso de surgencia activo. Sin embargo, concentraciones puntuales mayores de 1 y $5 \mu \mathrm{M}$ de fosfato y nitrato respectivamente, corresponden a valores superficiales altos, típicos de aguas de mayor profundidad. Esto, junto al leve ascenso hacia superficie de la termoclina estacional, y de las isolíneas de fosfato y nitrato en los primeros 10-15 m de profundidad en la zona costera, era indicativo del inicio del ascenso de aguas subsuperficiales más frías y ricas en nutrientes (Figs. 5a a 5f). La distribución del AESS presentó una leve inclinación hacia la superficie de las isolíneas de 10 a $30 \%$ en la zona costera (Fig. 6c), ascenso que fue asociado al inicio de un evento de surgencia.
El análisis de la información satelital e in situ, permite inferir que durante el 16 de enero, el sistema hidrográfico estaba comenzando a responder a la coacción del viento $\mathrm{S}$ y $\mathrm{SW}$ soplando a lo largo de la costa, el que en términos generales respondió al modelo de Ekman.

\section{Fase de madurez del evento de surgencia}

En los días 17 y 18, el transporte Ekman aumentó nuevamente y en promedio sobrepasó los $1.000 \mathrm{~m}^{3} \cdot \mathrm{s}^{-1}$ (Figs. 2a a 2c), mientras que la velocidad vertical aumentó de 0,02 a $0,07 \mathrm{~cm} \cdot \mathrm{s}^{-1}$ entre los días 16 y 18 , y la capa de Ekman de 9 a $21 \mathrm{~m}$. Las aguas cálidas de la capa superficial se alejaron de la costa, intensificándose las temperaturas bajas $\left(<13^{\circ} \mathrm{C}\right)$ y desapareciendo la termoclina estacional en el borde costero (Figs. 8a y 9a). Este aumento sostenido en el transporte de Ekman hacia fuera de la costa y el efecto topográfico de punta Curaumilla podrían ser responsables, en parte, de la presencia de la pluma de aguas frías con una dirección general de 45-55 hacia la izquierda del eje de la costa (Figs. 3b y 3c).

Durante este período del evento de surgencia, el desplazamiento mar adentro del ASAA y el ascenso hacia la superficie del AESS, típico de un evento de surgencia en la zona (Silva, 1973; Sievers \& Silva, 1979), provocó la disminución de temperatura y oxígeno disuelto, y el aumento en la salinidad y nutrientes superficiales en el borde costero, lo cual generó un fuerte gradiente horizontal costa-océano (Figs. 7a a 7f). En profundidad, las isolíneas de temperatura, salinidad, oxígeno disuelto y nutrientes mostraron un ascenso hacia la costa, lo cual provocó que en la franja costera, las salinidades y nutrientes fueran mayores, y la temperatura y oxígeno disuelto menores (Figs. 8a a 8f). Esto implicó que aguas con una proporción de mezcla del orden de 30 a $40 \%$ de AESS, alcanzaran la superficie en la zona costera, produciendo el desplazamiento del AST y del ASAA hacia el océano producto del ascenso del AESS (Figs. 6d a 6e).

Observaciones realizadas frente a la costa de Washington, asociadas a un evento de surgencia, muestran distribuciones verticales similares a las observadas en punta Curaumilla donde el agua del borde costero se hace más fría y con más nutrientes, generándose un gradiente costa-oceáno de temperatura y nutrientes (Brink, 1998).

Lo anterior permitió inferir que para el 18 de enero, el evento de surgencia había alcanzado su fase de madurez, abarcando un área mucho mayor que 
la observada in situ, según se pudo observar en las imágenes de la TSM. Estas imágenes también mostraron zonas costeras con agua fría más al norte $\left(32^{\circ} \mathrm{S}\right)$ (Fig. 3c), lo que implicaría una mayor extensión del evento en estudio o la presencia de otro evento independiente, más al norte.

\section{Fase de relajación del evento de surgencia}

El 20 de enero, último día de muestreo, el componente $\mathrm{S}$ del viento y el promedio del transporte Ekman disminuyeron notablemente $\left(<5 \mathrm{~m} \cdot \mathrm{s}^{-1}\right.$ y 600 $\mathrm{m}^{3} \cdot \mathrm{s}^{-1}$ respectivamente) (Figs. 2 b y $2 \mathrm{c}$ ), la velocidad vertical disminuyó a $0,001 \mathrm{~cm} \cdot \mathrm{s}^{-1}$ y la capa de Ekman a $3 \mathrm{~m}$, lo cual implicaría una relajación del evento en estudio y un retorno de las aguas cálidas hacia la costa. Sin embargo, la TSM mostraba que las condiciones de bajas temperaturas superficiales aún se mantenían respecto a las del día 18 (Fig. 3d).

Las mediciones in situ mostraron un desplazamiento hacia la costa de las isotermas mayores de $13^{\circ} \mathrm{C}$ y el restablecimiento de la termoclina estacional (Figs. 9a y 10a), lo cual se interpretó como el comienzo de la fase de relajación. Sin embargo, esta fase no estuvo bien definida, ya que durante el último día de muestreo aún persistía el viento SW, manteniendo un trasporte Ekman promedio de 600 $\mathrm{m}^{3} \cdot \mathrm{s}^{-1}$ (Fig. 2a a 2c).

Lo anterior provocó que la fase de relajación sólo fuera observada en su inicio, lo cual se manifestó en el hecho de que el 20 de enero, las isolíneas de salinidad, oxígeno disuelto y nutrientes aún presentaban una inclinación ascendente, aunque menor que la observada el 18 de enero (Figs. 10b a 10f). Por otra parte, en la franja costera las concentraciones superficiales de oxígeno disuelto aún eran bajas y los nutrientes altos, lo que es indicativo de remanentes de AESS cercanos a la superficie.

Los porcentajes de masas de agua, aún mostraban una distribución vertical ascendente del AESS, manteniendo el desplazamiento del AST y ASAA hacia el océano. Esto permitió que aguas con una proporción de mezcla de 30 a $40 \%$ de AESS aún permanecieran en la superficie en la zona costera (Figs. 6g a 6i).

Sievers \& Vega (2000), en un muestreo más prolongado, frente a Montemar, pudieron registrar la fase de relajamiento. En esa oportunidad las características hidrográficas, a $10 \mathrm{~m}$ de profundidad, disminuyeron de condiciones típicas de AESS (34,4 psu, $3 \mathrm{ml} \cdot \mathrm{L}^{-1}, 2,5 \mu \mathrm{M}$ en fosfato, $10 \mu \mathrm{M}$ en nitrato $\mathrm{y}$ $10 \mu \mathrm{M}$ en silicato), que corresponde a una situación de surgencia, a condiciones típicas de ASAA (32,2 psu, $5 \mathrm{ml} \cdot \mathrm{L}-1,1,5 \mu \mathrm{M}$ en fosfato, $4 \mu \mathrm{M}$ en nitrato y $4 \mu \mathrm{M}$ en silicato), que corresponde a una situación de relajación, lo cual no se presentó el 20 de enero.

Pese a lo anterior, el inicio de la fase de relajación se pudo definir basado en el restablecimiento de la termoclina estacional en el área costera (Fig. 10a). Por otra parte, al observar el gráfico del transporte de Ekman (Fig. 2c), se apreció que los valores promedios de los días 21 al 24 fueron cercanos a cero, e incluso negativos, lo que permite pensar que un muestreo adicional de tres a cuatro días más tarde, habría permitido detectar una situación de relajación completa, como la que observaron Sievers \& Vega (2000). Por su parte, la TSM mostró que el 23 y 24 de enero las aguas superficiales ya se estaban calentando, quedando las temperaturas menores de $14^{\circ} \mathrm{C}$, que caracterizaron al evento de surgencia en este estudio, confinadas sólo a una pequeña área alrededor de punta Curaumilla (Figs. 3e y 3f).

\section{AGRADECIMIENTOS}

Los autores desean agradecer a FONDECYT por financiar parcialmente esta investigación a través del Proyecto 1170/85 "Eventos de surgencia en la zona de Valparaíso y sus efectos en el ecosistema marino". Al patrón y tripulación del B/E "Tiberíades". A Reinaldo Rehhof y Noé Cáceres (QEPD), por el trabajo de toma de muestras. A Jorge Osorio por su labor en los análisis químicos, al Dr. Mario Cáceres por su cooperación en la preparación de la versión final del trabajo y a Claudio Silva del Laboratorio de Teledetección y SIG de la Pontificia Universidad Católica de Valparaíso por el re-procesamiento de las imágenes de temperatura del mar obtenidas por el satélite NOAA-F.

\section{REFERENCIAS}

Arcos, A. \& M. Salamanca. 1984. Distribución de clorofila y condiciones oceanográficas superficiales frente a Chile central (Latitudes $32^{\circ} \mathrm{S}-38^{\circ} \mathrm{S}$, Febrero 1982). Biol. Pesq., 13: 5-14.

Atlas, E., S. Hager, L. Gordon \& P. Park. 1971. A practical manual for use of the Technicon Autoanalyzer in sea water nutrient analyses. OSU Dept. of Oceanography, Technical Report, 215 pp. 
Bakun, A. 1978. Daily and weekly upwelling indices west coast of North America, 1967-73. U.S. Commer. NOAA Tech. Rep. NMFS-SSRS-693, $113 \mathrm{pp}$.

Blanco, J.L., A.C. Thomas., M.E. Carr \& P.T. Strub. 2001. Seasonal climatology of hydrographic conditions in the upwelling region off northern Chile. J. Geophys Res., 106(C6): 11451-11467.

Brandhrost, W. 1963. Descripción de las condiciones oceanográficas de las aguas costeras entre Valparaíso y Golfo de Arauco, con especial referencia al contenido de oxígeno y su relación con la pesca. (Resultados de la Expedición AGRIMAR, 1959). Ministerio de Agricultura, Dirección de Agricultura y Pesca, Santiago, Chile, 55 pp.

Brink, K.H. 1998. Wind-driven currents over the continental shelf, En: K.H. Brink \& A.R. Robinson (eds.).The global coastal ocean. Processes and methods. The Sea, Vol. 10. John Wiley \& Sons, New York. 3-20.

Cáceres, M. 1992. Vórtices y filamentos observados en imágenes de satélite frente al área de surgencia de Talcahuano, Chile central. Invest. Pesq. (Chile). 37: 55-66.

Carpenter, J.H. 1965. The Chesapeake Bay Institute thecnique for the Winkler dissolved oxygen method. Limnol. Oceanogr., 10: 141-143.

Cubillos, L.S. \& R. Fuenzalida. 1994. Indices de surgencia, turbulencia y ocurrencia de «eventos Lasker» en Iquique y Antofagasta (Chile) y su incidencia sobre los aspectos reproductivos de Sardinops sagax y Engraulis ringens. Cienc. Tecnol. Mar, Valparaíso, 17: 3-13.

Escribano, R., V.M. Marín \& P. Hidalgo. 2001. The influence of coastal upwelling on the distribution of Calanus chilensis in the Mejillones Peninsula (northern Chile): implications for its population dynamics. Hydrobiologia, 453(1-3): 143-151.

Escribano, R. \& P. Hidalgo. 2000. Spatial distribution of copepods in the north of the Humboldt Current region off Chile during coastal upwelling. J. Mar. Biol. Ass. UK, 80(2): 283-290.

Figueroa, D. \& C. Mofat. 2000. On the influence of topography in the induction of coastal upwelling along the Chilean coast. Geophys. Res. Lett., 27(23): 3905-3908.
Fonseca, T. \& M. Farías. 1987. Estudio del proceso de surgencia en la costa chilena utilizando percepción remota. Invest. Pesq. (Chile), 34: 34-46.

Hill, A.E., B.M. Hickey, F.A. Shillington, P.T. Strub, K.H. Brink, E.D. Barton \& A.C. Thomas. 1998. Eastern ocean boundaries. En:A.R. Robinson \& K.H. Brink (eds.). The global coastal ocean. Regional studies and syntheses. The Sea, Vol. 11. John Wiley \& Sons, New York. 29-78.

Marín, V., L. Rodríguez, L. Vallejo, J. Fuenteseca \& E. Oyarce. 1993. Efectos de la surgencia costera sobre la productividad primaria primaveral de bahía Mejillones del Sur (Antofagasta, Chile). Rev. Chil. Hist. Nat., 66: 479-491.

Montecino, V., G. Pizarro \& D. Quiroz. 1996. Phytoplankton dynamics in the upwelling-system off Coquimbo $\left(30^{\circ} \mathrm{S}\right)$ through the functional relationship between photosynthesis and irradiance (P-I). Gayana Oceanol., 4(2): 139-151.

Montecino, V. \& D. Quiroz. 2000. Specific primary production and phytoplankton cell size structure in an upwelling area off the coast of Chile $\left(30^{\circ} \mathrm{S}\right)$. Aquat. Sci., 62(4): 364-380.

Montecinos, A. \& F. Balbontín. 1993. Indices de surgencia y circulación superficial del mar: Implicancias biológicas en un área de desove de peces entre Los Vilos y Valparaíso, Chile. Rev. Biol. Mar., 28(1):133-150.

Rodríguez, L., M. Farías \& E. Oyarce. 1991. Identification of an upwelling zone by remote sensing and in situ measurements. Mejillones del Sur Bay (Antofagasta-Chile). Sci. Mar., 55(3): 467473.

Sievers, H. \& N. Silva. 1979. Variación temporal de las condiciones oceanográficas frente a punta Curaumilla, Valparaíso, Chile. (Mayo de 1974Abril de 1975). Inv. Mar., Valparaíso, 7(1): 3-20.

Sievers, H. \& S. Vega. 2000. Respuesta físico-química de la bahía de Valparaíso a la surgencia generada en punta Curaumilla y al fenómeno El Niño. Rev. Biol. Mar. Oceanogr., 35(2): 153-168.

Silva, N. 1973. Variaciones estacionales de temperatura, salinidad y contenido de oxígeno en la zona costera de Valparaíso (Septiembre de 1969-Agosto de 1970). Invest. Mar., Valparaíso, 4(3): 89-112. 
Silva, N. \& D. Konow. 1975. Contribución al conocimiento de las masas de agua en el Pacífico Sudoriental. Expedición Krill. Crucero 3-4. JulioAgosto 1974. Rev. Com. Perm. Pacífico Sur, 3: 6375.

Tam, J. \& F. Carrasco. 1999. Efectos de perturbaciones antropogénicas en el macrobentos sublitoral de una bahía eutrófica influenciada por surgencia costera en Chile central. Gayana, 63(1): 39-49.

Ulloa, O., R. Escribano, S. Hormazábal, R. Quiñones, R. González \& M. Ramos. 2001. Evolution and biological effects of the 1997-98 El Niño in the upwelling ecosystem off northern Chile. Geophys. Res. Lett., 28(8): 1591-1594.

Recibido: 29 abril 2003; Aceptado: 31 octubre 2003
Vergara, J. 1991. La surgencia costera a la latitud de $30^{\circ} \mathrm{S}$ : un estudio numérico. Rev. Biol. Mar., Valparaíso, 20(2): 375-401.

Vergara, J. 1992. Simulación de evento de surgencia costera a los $29,5^{\circ} \mathrm{S}$. Chile. Invest. Pesq., (Chile), 37: 73-87.

Weiss, W.J. 1970. The solubility of nitrogen, oxygen and argon in water and sea water. Deep-Sea Res., 17: 721-735.

Wu, J. 1982. Wind-stress coefficients over sea surface from breeze to huricane. J. Geophys. Res., 82: 9704-9706. 